\title{
STRESS TESTING OF PROBABILITY OF DEFAULT OF INDIVIDUALS
}

\author{
Petr Kadeřábek, Aleš Slabý, Josef Vodička*
}

\begin{abstract}
:
This paper introduces a model for stress testing of probability of default of individuals. The model rests on assumption that the individual defaults if his savings fall below zero. The probability of default is then described as a function of several macroeconomic indicators, such as wages, unemployment and interest rates. Stress testing is carried out by applying exogenous stress scenarios for development of these indicators. The model implies that sensitivity of probability of default to the stress is mainly driven by installment to income ratio and for mortgages also by loan maturity. Hence installment to income ratio is suggested as the appropriate tool to manage credit risk of retail portfolios.
\end{abstract}

Keywords: banking; credit risk; stress testing; probability of default

JEL Classification: G21, E32, E21

\section{Introduction}

Complex credit risk management in financial institutions addresses three levels of credit risk: expected losses, unexpected losses, and extreme events. Expected losses that are long-term average losses are covered by proper credit risk pricing and profitability management. Possible unexpected losses that are higher than long-term average losses are covered by capital reserves up to certain level of severity. Extreme unexpected losses above the severity level shall be rare by definition and hence it is not efficient to keep reserves for them continuously. However, the institution should foresee impact of extreme events which could evolve from current situation and it has to have a plan for each such event to mitigate its impact if it evolves. This task is supported by stress testing.

Stress testing is, in other words, investigation of an impact of meaningfully defined scenarios of future development, extreme development in particular. In credit risk stress testing, an impact of these scenarios is measured in terms of losses to be suffered on account of credit risk or in terms of change in credit risk parameters. This paper focuses

* Komerční banka, a.s., Praha; The Institute of Economic Studies of the Charles University, Praha (petrkaderabek@seznam.cz); Komerční banka, a.s., Praha (ales_slaby@kb.cz); Komerční banka, a.s., Praha; Société Genérale, Paris (Josef.Vodicka@socgen.com). 
on impact of adverse macroeconomic development on probability of default (PD) of individuals.

In line with Vasicek (2002), the background for Basel II model of unexpected losses, we consider two types of credit risk factors affecting probability of default: global (systemic) and individual (idiosyncratic). Individual factors are specific for each transaction and are averaged in diversified portfolio. Global factors are common to all transactions in the portfolio and can be interpreted as the macroeconomic conditions. Hence the macroeconomic variables are in the center of our interest and are viewed as drivers of key individual factors, such as income and level of savings.

In literature, an impact of the macroeconomic environment on credit risk has been studied from two perspectives. A bottom-up approach is based on data of individual clients while a top-down approach relies on aggregate data. This paper adopts the bottom-up approach similarly as Gross and Souleles (2001), who inspect stability of the credit risk models of the US households using the panel data set of credit cards. A top-down approach is more common in the literature as the aggregate data are more easily available: The time-series approach to modelling the arrears of UK individuals using the macroeconomic data is adopted by Whitley, Windram and Cox (2004). A latent-factor model is developed by Jakubík (2007), which is then applied to the Czech banking sector.

When modelling credit stress in the Czech Republic the following issues are faced regarding macroeconomic variables:

- The transitive economy has not experienced regular economic cycle. The economic downturn in the 1990s was driven by specific economic conditions that are not likely to be repeated.

- In last ten years the economic conditions have gradually improved.

- Retail banking business has been dynamically developing within a relatively short time from almost zero to its contemporary complexity.

Moreover, the portfolio is usually closely controlled by the Risk Management and hence we will develop a theoretical macroeconomic model rather than any statistical model. A clear story behind the results is also an advantage of this approach so that it can better serve "as a diagnostic tool to improve the institution's understanding of its risk profile". It is another important reason for stress testing as pointed out by the Committee of European Banking Supervisors (2006).

The fundamental paper in the field of corporate default rate modelling and bond pricing is by Merton (1974). This paper deals with modelling default rate of individual clients, which is not a topic frequently discussed in literature. We adopt the approach by Merton (1974) and modify it for the loans of individuals. Heřmánek et al. (2007) refer to "different sensitivities of corporations and households to the macroeconomic environment" which supports the need to build the model for individual clients differently.

Merton (1974) states that "on the maturity date, the firm must either pay the promised payment to the bondholders or else the current equity will be valueless. "He concludes that the firm will default if the value of equity is lower than the promised payment. This conclusion is based on the assumption that "the firm cannot issue any 
new senior (or of equivalent rank) claims on the firm nor it cannot pay cash dividends or repurchase shares prior to the maturity date of the debt".

If we adopted this approach to the case of individuals, we would state that the client defaults if and only if the value of his property (incl. the net present value of his future income) is lower than the promised payment. However, an assumption that the client cannot issue any claims on his property is not as realistic as it is in the case of firms. Hence, we will abstract of the client's property and focus solely on his income and savings.

The paper is organized as follows: Section 2 introduces the underlying dynamic model of client's income and savings. In Section 3, the default is defined and sensitivity of probability of default to changes of macroeconomic variables is investigated. Section 4 deals with issues concerning implementation of the model. In Section 5, an example of results of the model is presented. Section 6 concludes.

\section{Model of Income and Savings}

In this section, we will develop a dynamic model of individual's income and savings. The model will be used later for computation and stress of PD.

The following notation will be used throughout the paper: Macro variables are denoted by capital letters while the variables concerned with an individual client or a loan are denoted in lower case.

The nominal income $i_{t}$ is divided between the consumption $c_{t}$, sum of all annuity payments $a_{t}$ and deposit $s_{t}-s_{t-1}\left(1+r_{t-1}^{s}\right)$,

$$
i_{t}=c_{t}+a_{t}+\left[s_{t}-s_{t-1}\left(1+r_{t-1}^{s}\right)\right],
$$

where $s_{t}$ is the amount of savings and $r_{t-1}^{s}$ is an interest rate on savings per one interest period. To simplify formulae, refer to savings accrued in time $t$ as

$$
s_{t}^{*} \equiv s_{t-1}\left(1+r_{t-1}^{s}\right) \text {. }
$$

We conservatively assume that each client who is borrowing money has not available savings in the time of loan granting, i.e.

$$
s_{0}=0 .
$$

If the client has savings at the time of loan granting he will spend them and borrow only the rest of money needed.

Let consumption $c_{t}$ depend linearly on disposable income plus savings coming from the previous period, namely,

$$
c_{t}=\gamma^{*} P_{t}+\gamma \cdot\left[s_{t}^{*}+i_{t}-a_{t}-\gamma^{*} P_{t}\right],
$$

where $\gamma^{*}$ is the client's minimum level of real consumption and it is assumed to be constant over time, $P_{t}$ is a price level in time $t$. Hence, $\gamma^{*} P_{t}$ is the client's minimum nominal consumption. The linear relationship was used due to the algebraical simplicity of the results. 
The coefficient $\gamma \in[0,1]$ is a marginal propensity to consumption. When the client's income (or savings coming from the previous period) increases by $1 \mathrm{CZK}$ his nominal consumption increases by $\gamma$ CZK.

Dynamics of savings can be described using (1) and (4) as

$$
\begin{aligned}
s_{t} & =s_{t}^{*}+i_{t}-a_{t}-c_{t} \\
& =s_{t}^{*}+i_{t}-a_{t}-\gamma^{*} P_{t}-\gamma \cdot\left[s_{t}^{*}+i_{t}-a_{t}-\gamma^{*} P_{t}\right] . \\
& =(1-\gamma) \cdot\left[s_{t}^{*}+i_{t}-a_{t}-\gamma^{*} P_{t}\right], \\
& =(1-\gamma) \cdot\left[s_{t-1}^{*}\left(1+r_{t-1}^{s}\right)+i_{t}-a_{t}-\gamma^{*} P_{t}\right],
\end{aligned}
$$

Variables $a_{t}$ and $P_{t}$ are given exogenously, dynamics of income $i_{t}$ is specified hereunder.

Denote $i_{0}$ the equilibrium client's income in time 0 and $I_{t}$ the nominal per capita income in the economy in time $t$. Assume that $\ln \left(i_{t} / I_{t}\right)$ is the AR(1) process with intercept. The intercept term is given by the ratio of the client's equilibrium income to the per capita income in the economy. This ratio is assumed to be constant over time.

Hence, we can write the income equation as

$$
\ln \frac{i_{t}}{I_{t}}=\alpha \ln \frac{l_{0}^{-}}{I_{0}}+(1-\alpha) \ln \frac{i_{t-1}}{I_{t-1}}+\varepsilon_{t},
$$

where $(1-\alpha)$ is an autoregression coefficient such that $0<\alpha<1$, and assume that $\varepsilon_{t}$ has a distribution with zero mean. Logarithm of income in time $t$ can be expressed as

$$
\ln i_{t}=\alpha \ln \frac{i_{0}^{-}}{I_{0}}+(1-\alpha) \ln \frac{i_{t-1}}{I_{t-1}}+\ln I_{t}+\varepsilon_{t} .
$$

\section{Probability of Default}

\subsection{Definition of Default}

For the sake of definition of default let us assume that the client cannot borrow additional money or restructure the debt. Hence default occurs when client's income plus savings coming from the previous period do not cover the installments plus minimum consumption, i.e. $s_{t}{ }^{*}+i_{t}<a_{t}+\gamma^{*} P_{t}$. By equation (5), this is equivalent to the condition when the current volume of savings falls to negative values, $s_{t}<0$.

Let us define the default formally. Let $\mathrm{D}_{t}$ be the random event that the client is in default in time $t$. Then

$$
\mathrm{D}_{t} \Leftrightarrow s_{t}<0
$$

$\mathrm{D}_{t}$ will be studied in sensitivity analysis.

Analogically let $\mathrm{D}_{1, t}$ be the event that the client defaulted in time period from 1 to $t$,

$$
\mathrm{D}_{t} \Leftrightarrow \min _{k=1, \ldots t}\left\{s_{t}\right\}<0 .
$$

$\mathrm{D}_{1, t}$ will be studied in PD dynamics analysis. 


\subsection{Sensitivity Analysis}

We will determine the transaction-specific factors affecting sensitivity of PD to the stress of macroeconomic conditions. It will allow identifying potentially risky parts of retail portfolios.

When performing the sensitivity analysis, we will start with a given (typically expected) PD in time $t$ under the given loan parameters and macroeconomic conditions in time $t$ and $t-1$. We will inspect change of PD caused by a change (stress) in macroeconomic conditions in time $t$ having all the parameters in time $t-1$ constant. The variables concerned with the changed conditions will be marked by a prime, e.g. $P_{t}{ }^{\text {' }}$, while the original variables remain denoted in the simple way, e.g. $P_{t}$.

Denote $p_{t}$ the probability that the client is in default in time $t$,

$$
p_{t} \equiv \mathrm{P}\left[\mathrm{D}_{t}\right]
$$

Our goal is to express the stressed PD $p_{t}$ 'using $p_{t}$ and the macroeconomic variables, both original and stressed.

For expectation of $\ln i_{t}$ given by (7) we have conditionally on information prior to t:

$$
\begin{aligned}
\ln \hat{\imath}_{t} & \equiv \mathrm{E}_{t-1}\left[\ln i_{t}\right] . \\
& =\alpha \ln \frac{\bar{l}_{0}}{I_{0}}+(1-\alpha) \ln \frac{i_{t-1}}{I_{t-1}}+\ln I_{t} .
\end{aligned}
$$

Since values of variables from time $t-1$ are known in time $t$ and $I_{t}$ is exogenous, all the variables involved in equation (11) are deterministic and therefore

$$
\frac{\hat{\imath}_{t}}{\hat{\imath}_{t}^{\prime}}=\frac{I_{t}}{I_{t}^{\prime}}
$$

Definition of default (8), model specification (5) and (7), and equation (11) imply that

$$
\begin{aligned}
& p_{t}=\mathrm{P}\left[s_{t}<0\right] \\
& =\mathrm{P}\left[i_{t}<\gamma^{*} P_{t}+a_{t}-s_{t}^{*}\right] \\
& =\mathrm{P}\left[\frac{i_{t}}{\hat{\imath}_{t}}<\frac{\gamma^{*} P_{t}+a_{t}-s_{t}^{*}}{\hat{\imath}_{t}}\right] \\
& =\mathrm{P}\left[\exp \left(\varepsilon_{t}\right)<\frac{\gamma^{*} P_{t}+a_{t}-s_{t}^{*}}{\hat{\imath}_{t}}\right] \\
& =F\left[\frac{\gamma^{*} P_{t}+a_{t}-s_{t}^{*}}{\hat{\imath}_{t}}\right] .
\end{aligned}
$$

where $F$ is the $\mathrm{CDF}$ of $\exp \left(\varepsilon_{t}\right)$.

Let us assume that

$$
p_{t}>0 \text {. }
$$


When $F$ is increasing, we can uniquely define $F^{-1}\left[p_{t}\right]$ and express the consumption level under zero disposable income as

$$
\gamma^{*}=\frac{\hat{i}_{t} F^{-1}\left[p_{t}\right]-a_{t}+s_{t}^{*}}{P_{t}} .
$$

It is assumed to be positive, which is equivalent to the condition

$$
p_{t}>F\left[\frac{a_{t}-s_{t}^{*}}{\hat{l}_{t}}\right] \text {. }
$$

Using the stressed values (marked by prime) we obtain an equation analogical to (13)

$$
p_{t}^{\prime}=F\left[\frac{\gamma^{*} P_{t}^{\prime}+a_{t}^{\prime}-s_{t}^{*}}{\hat{\imath}_{t}^{\prime}}\right] .
$$

After substitution of equation (15) into (17) and due to (12),

$$
p_{t}^{\prime}=F\left[\frac{I_{t} / P_{t}}{I_{t}^{\prime} / P_{t}^{\prime}}\left(F^{-1}\left[p_{t}\right] \frac{a_{t}}{\hat{\imath}_{t}}\left(\frac{a_{t}^{\prime}}{a_{t}} \cdot \frac{P_{t}}{P_{t}^{\prime}}-1\right)-\frac{s_{t}^{*}}{\hat{\imath}_{t}}\left(\frac{P_{t}}{P_{t}^{\prime}}-1\right)\right)\right] .
$$

The ratio $a_{t} / \hat{l}_{t}$ will be called installment to income ratio (IIR), $s_{t}{ }^{*} / \hat{\imath}_{t}$ is referred to as the savings to income ratio (SIR) in the next paragraphs.

Discussion of the theoretical findings derived can be found in section 5.1.

\subsection{Force of Habit: An Alternative Approach}

In this section, we present a less traditional approach. It leads to simpler results and may be more realistic for some economists. It is presented as a possible alternative only and will not be discussed in the next sections.

We can use the per capita consumption $C_{t}$ instead of the price index, i.e. set

$$
P_{t}=C_{t} .
$$

Justification of this approach is in the work of Abel (1990), who argues that the individual's utility depends on the ratio of his consumption to the lagged ${ }^{1}$ cross-sectional average level of consumption. This approach is now popular in financial theory; see for example Campbell and Cochrane (1999).

To illustrate its reasonability on the practical example, consider a mortgage lasting 20 years. In the year 1988, which is exactly 20 years ago, people had no cell phones. In the year 2008, a cell phone belongs to the necessary equipment and people must buy it for their income. This rise of expenditures is not contained in the consumer price index.

1 We will use the non-lagged average level of consumption because it results in a simpler formula but the lagged consumption could be employed as well. 
When cell phones (similarly as any other goods) entered CPI, only weights of the goods changed and it caused no immediate inflation. On the other hand, it was immediately reflected in the rise of per capita consumption.

Adopting this approach to our model, the former minimum real consumption $\gamma^{*}$ would then express the minimum consumption relative to the per capita consumption in the economy. Loosely speaking, $\gamma^{*}$ is the minimum living standard of the client relative to his neighbours.

Let us assume that on macroeconomic level, per capita consumption is the constant proportion of per capita income $I_{t}$,

$$
C_{t}=\rho I_{t} .
$$

Hypothesis of $I_{t} / C_{t}$ constancy on the U.S. economy data spanning from Q1 1974 to Q1 1998 is discussed by Hayashi (2000), p. 648. The cointegration test of $\ln I_{t}$ and $\ln C_{t}$ (without the intercept term) is performed with the null hypothesis of no cointegration. His results reject the null hypothesis of no cointegration on the subsample from Q1 1950 to Q4 1986, hence support cointegration. On the whole sample, the null hypothesis of no cointegration is not rejected. The reason is the declining personal saving rate from the mid 1980s. However, for our purposes, assumption of the constant personal saving rate is realistic enough.

By equations (19) and (20), $P_{t}$ is defined as

$$
P_{t}=\rho I_{t},
$$

hence the price level is no longer necessary. Then, equation (5) becomes

$$
\begin{aligned}
s_{t} & =(1-\gamma) \cdot\left[s_{t}^{*}+i_{t}-a_{t}-\gamma^{*} \rho I_{t}\right] . \\
& =(1-\gamma) \cdot\left[s_{t-1}^{*}\left(1+r_{t-1}^{s}\right)+i_{t}-a_{t}-\gamma^{*} \rho I_{t}\right] .
\end{aligned}
$$

Assumptions about $i_{t}$ dynamics remain unchanged and hence equations (7) and (11) hold.

Now we can provide the sensitivity analysis under the new assumptions. By (21), equation (18) becomes

$$
p_{t}{ }^{\prime}=F\left[F^{-1}\left[p_{t}\right]+\frac{a_{t}}{\hat{\imath}_{t}}\left(\frac{a_{t}{ }^{\prime}}{a_{t}} \cdot \frac{I_{t}}{I_{t}{ }^{\prime}}-1\right)-\frac{s_{t}^{*}}{\hat{\imath}_{t}}\left(\frac{I_{t}}{I_{t}{ }^{\prime}}-1\right)\right] .
$$

We can see that ratio of the changed and original real income does not affect $p_{t}^{\prime}$ anymore. Justification is that both the income and average consumption (used instead of the price level) changes proportionally with the per capita income. In other aspects, conclusions are similar to those of equation (18).

\section{Model Implementation}

This part of the paper deals with issues concerning calibration of the theoretical models established heretofore. Tentative scenarios of future development of the Czech 
economy are given exogenously and referred to in Section 4.1. Section 4.2 discusses relationship between the loan interest rate and interest rate in the economy. Annuity dynamics in case of re-fixes is inspected in Section 4.3. Distribution of income change is selected in Section 4.4.

\subsection{Stress Testing Scenarios}

Trajectories for development of the economy are exogenous to our model. Several tentative scenarios are provided, covering beside the expected development the following unfavourable types of evolution: recession and growing interest rates.

Expected scenario is the point prediction of macroeconomic development. Recession will negatively affect incomes, i.e. wages decline and unemployment increases. Scenario with growth of interest rates is crucial for mortgage loans stress testing.

\subsection{Interest Rates}

For the loans that are assumed to be re-fixed in the future, the new loan nominal interest rate per one period $r_{t}$ must be computed. Denote $R_{t}$ interest rate per one period in the economy.

For simplicity we will assume a constant additive gross margin. Hence if the loan is re-fixed in time $t>0$, its new interest rate will be

$$
r_{t}=r_{0}-R_{0}+R_{t}
$$

where $R_{t}$ is a nominal interest rate in the economy in time $t$.

\subsection{Annuity Dynamics}

For simplicity let us assume in this section that the client has only one loan subject to interest rate refix. Let $a_{t}$ and $v_{t}$ denote annuity and residual outstanding amount of the loan as at time $t$. As refixes are usual only for mortgages this assumption is realistic, moreover, it is only a technical complication to generalize the analysis for more loans with annuity change.

For consumer loans, annuity is constant over the whole life of the loan. For vanilla mortgage loans, annuity changes take place in agreed time of contract re-fix and depend on the interest rate as at the time of refix.

Let us assume that re-fix takes place in time $t$. Maturity $n$, typically in months, will be expected to be fixed, i.e. only annuity, not time to maturity, changes in the time of re-fix.

Let us denote $\tau$ time of previous interest rate fixation or loan granting. Then the residual outstanding amount in time $t$ can be computed as the amount that remains to be paid with annuity $a_{\tau}$ and nominal interest rate $r_{\tau}$ for $n-t$ months, namely,

$$
v_{t}=a_{\tau} \frac{\left(1+r_{t}\right)^{n-t}-1}{r_{\tau}\left(1+r_{\tau}\right)^{n-t}} .
$$


New annuity after re-fix in time $t$ can be derived from $v_{t}$ as

$$
a_{t}=v_{t} \frac{r_{t}\left(1+r_{t}\right)^{n-t}}{\left(1+r_{\tau}\right)^{n-t}-1},
$$

and after substitution from equation (25) as

$$
a_{t}=a_{\tau} \frac{r_{t}}{r_{\tau}} \cdot \frac{\left(1+r_{t}\right)^{n-t}}{\left(1+r_{\tau}\right)^{n-t}} \cdot \frac{\left(1+r_{\tau}\right)^{n-t}-1}{\left(1+r_{t}\right)^{n-t}-1} .
$$

For the sensitivity analysis, we need the ratio of the changed and original annuity. Information prior to time $t-1$ is known and hence $a_{\hat{o}}$ and $r_{\hat{o}}$ remain unchanged. Ratio of the changed and original annuity can be then expressed as

$$
\frac{a_{t}{ }^{\prime}}{a_{t}}=\frac{r_{t}{ }^{\prime}}{r_{\tau}} \cdot \frac{\left(1+r_{t}{ }^{\prime}\right)^{n-t}}{\left(1+r_{\tau}\right)^{n-t}} \cdot \frac{\left(1+r_{\tau}\right)^{n-t}-1}{\left(1+r_{t}{ }^{\prime}\right)^{n-t}-1} .
$$

\subsection{Distribution of Income Change}

Loans can be paid off from various sources of income, such as wage, rent, interests, dividends etc. However, wage strongly prevails for most clients and hence we will focus on this source of income in our analysis.

Income should reflect also the possibility of being unemployed. When losing a job the client receives social aid from the state. Other sources of income in such situation may be: withdrawal of savings, work in the grey economy or help of client's family or friends. We will assume that possible unemployment is already incorporated in the process of income.

In equation (7), $\varepsilon_{t}$ is assumed to have a distribution with zero mean. Here tentatively assume that $\varepsilon_{t} / \sigma$ has a Student distribution with $d>1$ degrees of freedom, its CDF will be denoted $G$. (Note that mean of the Student distribution with $d>1$ degrees of freedom is 0 .) Then,

$$
F[x] \equiv G[(\ln x) / \sigma ; d],
$$

where $\sigma>0$ is the scaling factor.

\section{Results}

\subsection{Sensitivity Analysis}

Sensitivity to the stress varies across clients. We will determine its main drivers in this section using the theoretical findings from Section 3.2 with details about annuity and income change distribution from sections 4.3 and 4.4 .

Remind that the sensitivity analysis studies one-period changes and period of annuity payment is usually one month. Parameters of the model will be chosen with 
respect to this fact. They will reflect the scenario of growing interest rates, inflation and real income, which will turn out to be the riskiest one for mortgages.

The stressed annual loan interest rate will be probably $0.25 \%$ or at most $0.5 \%$ above the expected rate. For the annual expected interest rate of $5.5 \%$, the expected monthly rate is $r_{t}=0.055 / 12$ and the stressed will be chosen $r_{t}{ }^{\prime}=0.0575 / 12$. Figure 1 (in appendix) shows dependence of the annuity stress on the stress of interest rates. The sensitivity increases with the growing time to maturity. For the typical mortgage loan 240 months to maturity and discussed $r_{t}, r_{t}{ }^{\prime}$ we have $a_{t}{ }^{\prime} / a_{t} \approx 1.02$. This value is used in the graph of equation (18), see Figure 2.

Growing interest rates are usually accompanied by the increase of inflation. We will assume a monthly price level stress by $0.5 \%$. The stressed real income is assumed to increase also by $0.5 \%$ and so the nominal income grows by $1 \%$.

Client's IIR is chosen to be 0.6 and SIR 0.2. Parameters of the income distribution are set to be $d=4$ and $\sigma=0.02$.

Impact of IIR and SIR is depicted in the upper two graphs of Figure 2. IIR has clearly a greater effect on the PD stress because real annuity change is higher than the price level stress. Sensitivity to the choice of the distribution parameters is presented in the middle part of the figure, details of the two graphs for $p_{t}<0.1$ are plotted below. While the degrees of freedom $d$ impact the stress significantly less than the scale parameter $\sigma$ for $p_{t} \approx 0.5$, the situation is exactly opposite for $p_{t} \approx 0$ (the case of most loans).

To sum up, the following transaction-specific drivers of sensitivity to stress were identified: IIR, SIR and the time to maturity.

IIR determines the sensitivity of PD change caused by the stress of real annuity. The nominal annuity is either constant (consumer loans) or may be changed (mortgages). Its change is then caused by the stress of loan interest rate and the extent is determined by the time to maturity. Another factor contributing to real annuity and the only one for consumer loans is the price level. It is relatively less volatile than the nominal annuity in time of re-fix.

SIR expresses sensitivity to the stress of price level. The purchasing power of savings depends on the price level, hence clients with relatively high savings are subject to risk of price level stress but, on the other hand, they are generally less risky than those with no savings. However, level of savings depends on client's decision and cannot be directly influenced by the financial institution.

Hence, the most risky segment is mortgages with principal risk drivers being large IIR and long time to maturity.

\subsection{Dynamics of PD}

We will demonstrate the dynamic model on the example in this section. The exogenous scenarios of macroeconomic development are presented in Figure 3. They specify the annual interest rate $12 R_{t}$, index of per capita income $I_{t}$ (wages adjusted for the income of the unemployed) and price level index $P_{t}$. The time period is equal to one month.

Realization of client's savings and income development was performed via equations (5) and (7) using error terms of the income change $\varepsilon_{t}$ generated from the distribution (29). This step was repeated 1000000 times and rates of default computed. 
The following loan and client properties were used in the simulation:

$$
\begin{aligned}
a_{0} & =12000 \mathrm{CZK} \\
\bar{\imath}_{0}=i_{0} & =20000 \mathrm{CZK} \\
\gamma^{*} P_{t} & =5000 \mathrm{CZK} \\
n & =240 \\
r_{0} & =0.055 / 12 \\
r_{t}^{s} & =0 \\
\gamma & =0.5 \\
\alpha & =0.05 \\
\sigma & =0.02 \\
d & =4
\end{aligned}
$$

In the first example, loan interest rate is re-fixed each 12 months using the algorithm described in section 4.2. This is the case of a mortgage loan. Results can be seen in Figure 4. In the first graph there is the mortality function from the time of loan granting till the time $t$. The second graph describes probability of default in time $t$ of the loans performing till time $t-1$. The third and fourth graph depicts development of annuity and loan interest rate in time.

In the second example, parameters of the loan are the same but annuity is constant over the whole life of the loan (or at least for the observed period). This may be the case of consumer loan or mortgage loan with a long fixation period. Note that maturity of the loan does not matter in this case. Default rates are depicted in Figure 5.

In both examples but especially in the second one, we can observe peak in $\mathrm{P}\left[\mathrm{D}_{t} \mid \neg \mathrm{D}_{1, t-1}\right]$ in time $t=1$. It is due to the fat-tailed distribution of income change: The peak is even more significant for $d=1$ and not present for $d=\infty$.

The gradual increase of $\mathrm{P}\left[\mathrm{D}_{t} \mid \neg \mathrm{D}_{1, t-1}\right]$ after time $t=2$ is caused by decreasing income of part of the clients. Contrary to this acts the effect of increasing average savings of those who did not default, which prevails in our example after the time of $t \approx 10$, when PD starts to decline.

While in the second example no serious impact of different scenarios on PD is observed we have identified a serious risk of interest rate increase in the first example. It is caused by re-fixation of mortgage loans, when annuity substantially increases and causes the immediate growth of the probability of default of the non-defaulted loans in the next months.

\section{Conclusion}

We proposed a dynamic macroeconomic model of individual client's PD. Scenarios of macroeconomic development and eventual fixation periods were specified exogenously.

The transaction-specific drivers of sensitivity to the stress were identified to be IIR, SIR and for mortgages also time to maturity. IIR determines sensitivity to the stress in real annuity, which is either given solely by the price level stress for the fixed nominal annuity or contains also nominal annuity change depending on the interest rate stress and time to maturity. SIR expresses sensitivity to the stress of price level. Although 
clients with high SIR are more sensitive to the stress, they are generally less risky. However, level of savings cannot be directly influenced by the financial institutions.

In the empirical simulation, an important risk was found in the segment of mortgages under the scenario of growing interest rates. IIR and time to maturity are the key risk drivers in this case.

This conclusion sends also another clear message: Potential allowing for higher IIR and maturity length for mortgages in the granting process should be treated carefully.

An alternative approach based on the habit formation was presented. It does not require the exogenous price level and yields simpler results. Conclusions under this approach are similar.

\section{References}

Abel, A. (1990), "Asset Prices under Habit Formation and Catching Up with the Joneses." American Economic Review, 1990, 80, pp. 38-42.

Campbell, J. Y., Cochrane, J. H. (1999), "By Force of Habit: A Consumption-Based Explanation of Aggregate Stock Market Behavior." The Journal of Political Economy, 1999, 107 (2), pp. 205-251.

Committee of European Banking Supervisors (2006), "Technical Aspects of Stress Testing under the Supervisory Review Process." CEBS Consultation Paper 12, 2006.

Gross, D. B., Souleles, N. S. (2001), "An Empirical Analysis of Personal Bankruptcy and Delinquency." National Bureau of Economic Research Working Paper 8409, 2001.

Hayashi, F. (2000), Econometrics. Princeton: Princeton University Press, 2000.

Heřmánek, J., Hlaváček, M., Jakubík, P. (2007), "Credit Risk, Credit Growth Models and Stress Testing." CNB Economic Research Bulletin, 2007, 1, pp. 2-5.

Jakubík, P. (2007), "Macroeconomic Environment and Credit Risk." Czech Journal of Economics and Finance (Finance a úvěr), 2007, 57, pp. 60-78.

Merton, R. (1974), "On the Pricing of Corporate Debt: The Risk Structure of Interest Rates." Journal of Finance, 1974, 29, pp. 449-470.

Vasicek, O. (2002), "The Distribution of Loan Portfolio Value." Risk, 2002, 15, pp. 160-162.

Whitley, J., Windram, R., Cox, P. (2004), "An Empirical Model of Household Arrears." Bank of England Working Paper 214, 2004.

\section{APPENDIX}

Figure 1

Results of Equation (28) for $r_{t}=0.055 / 12$, i.e. $5.5 \%$ p.a.

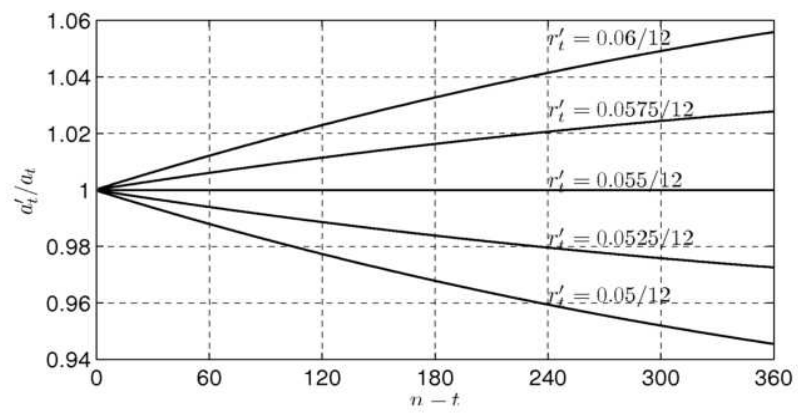


Figure 2

Sensitivity of PD to the Change of Parameters.
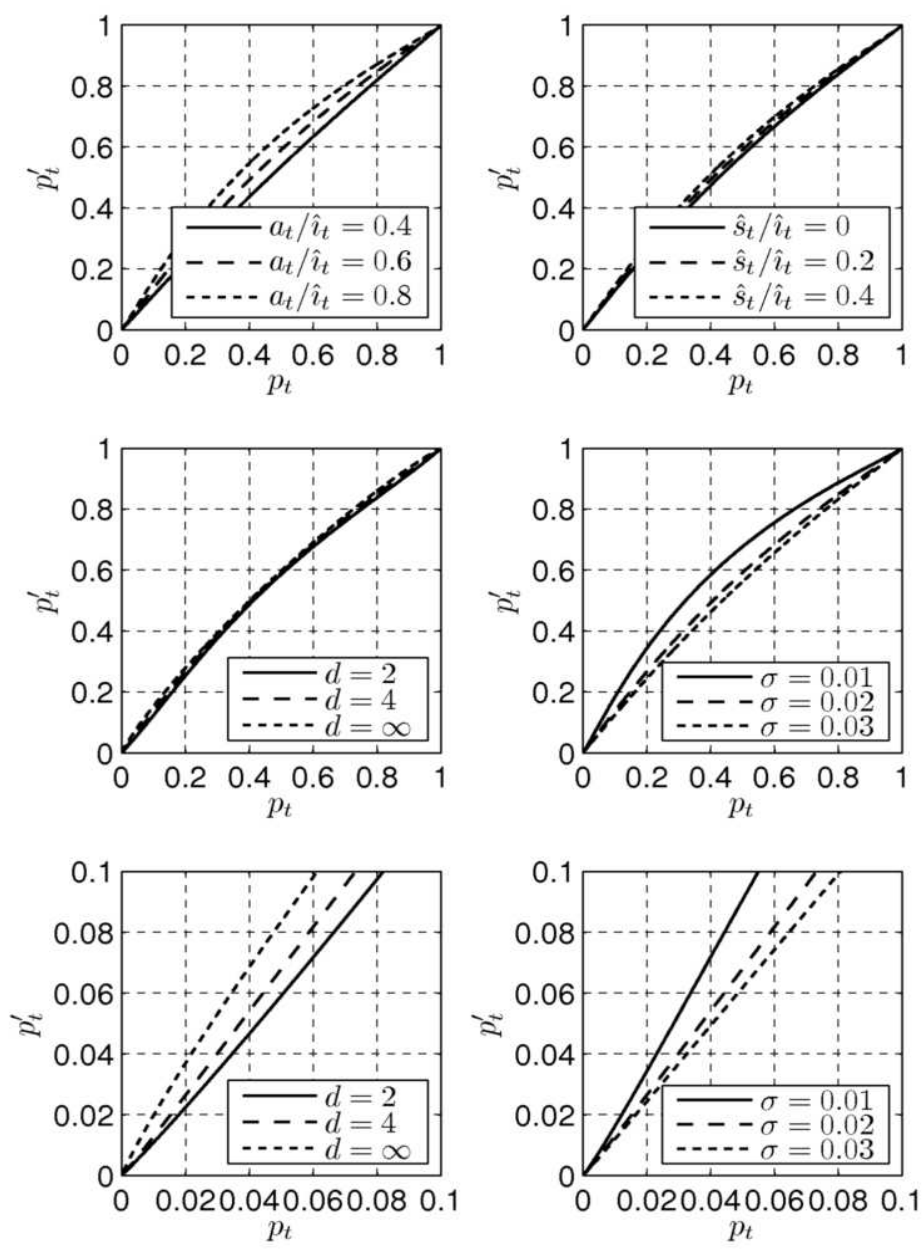

Note: The reference values are IIR $a_{t} / \hat{l}_{t}=0.6, \operatorname{SIR} s_{t}{ }^{*} / \hat{\imath}_{t}=0.2$, price level stress $P_{t}{ }^{\prime} / P_{t}=1.005$, per capita income stress $I_{t}{ }^{\prime} / I_{t}=1.01$, annuity stress $a_{t}{ }^{\prime} / a_{t}=1.02$, degrees of freedom $d=4$, scaling parameter $\sigma=0.02$, if not specified differently in the graph. 


\section{Figure 3}

Scenarios of the Macroeconomic Development: Interest Rate p.a. $12 R_{t}$, Index of per capita Income $I_{t}$ and Price Level Index $\boldsymbol{P}_{t}$.

- Expected scenario - - - Recession Growing interest rates
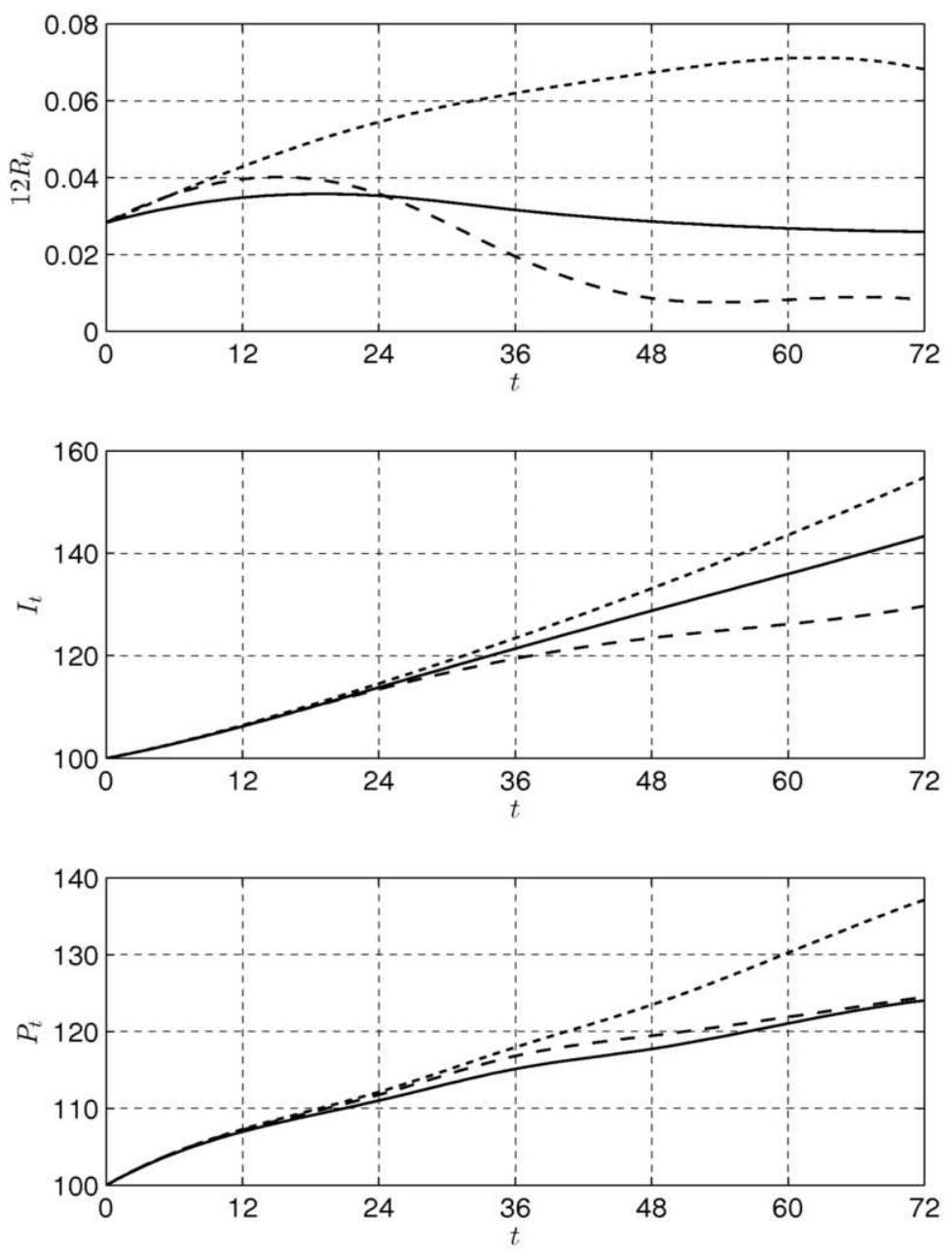
Figure 4

Annuities and PD's under Different Scenarios with Re-fix Each 12 Periods (months)

— Expected scenario _ - - Recession -.-.. Growing interest rates
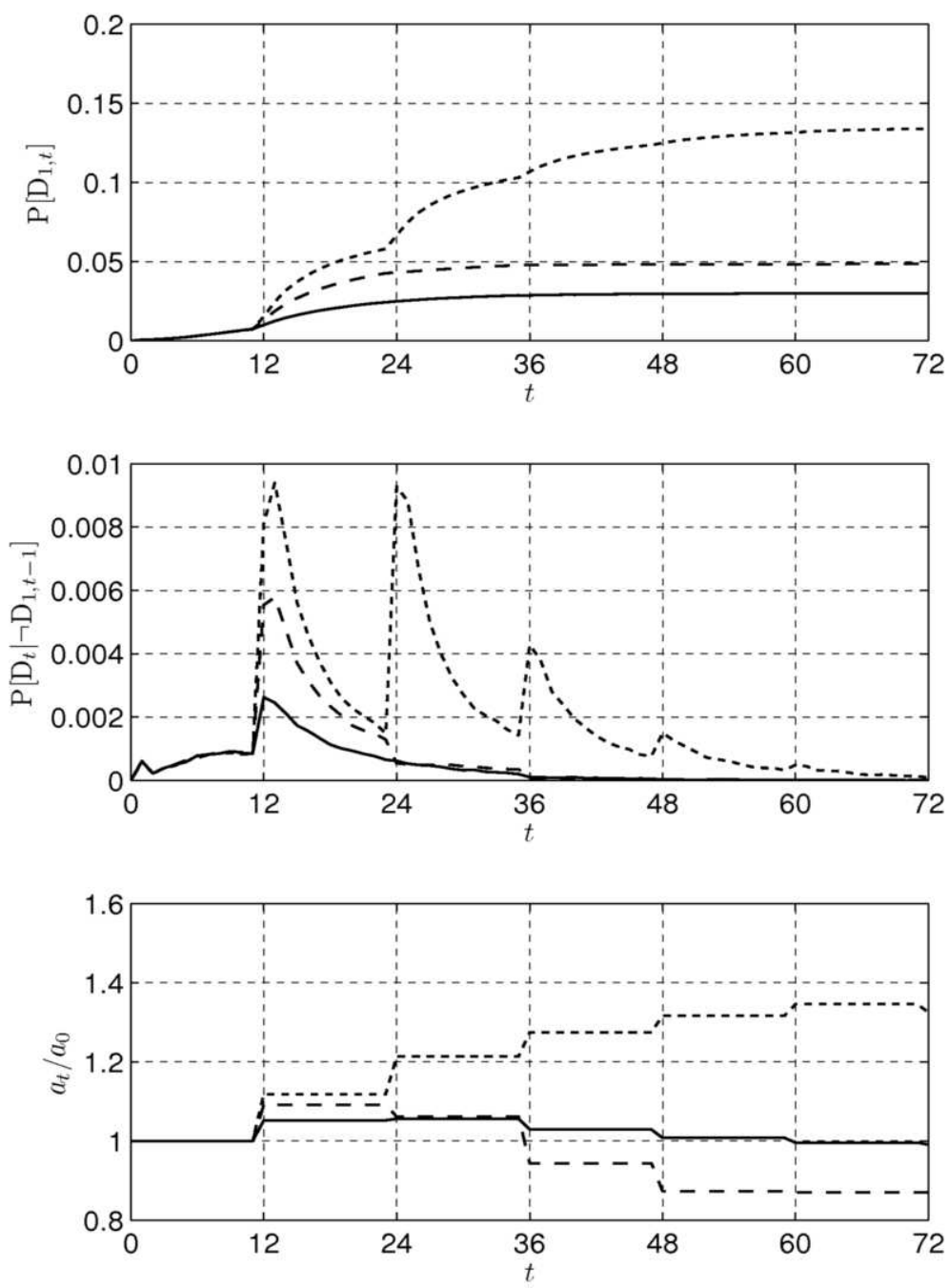
Figure 5

PD's under Different Scenarios with Constant Annuity.
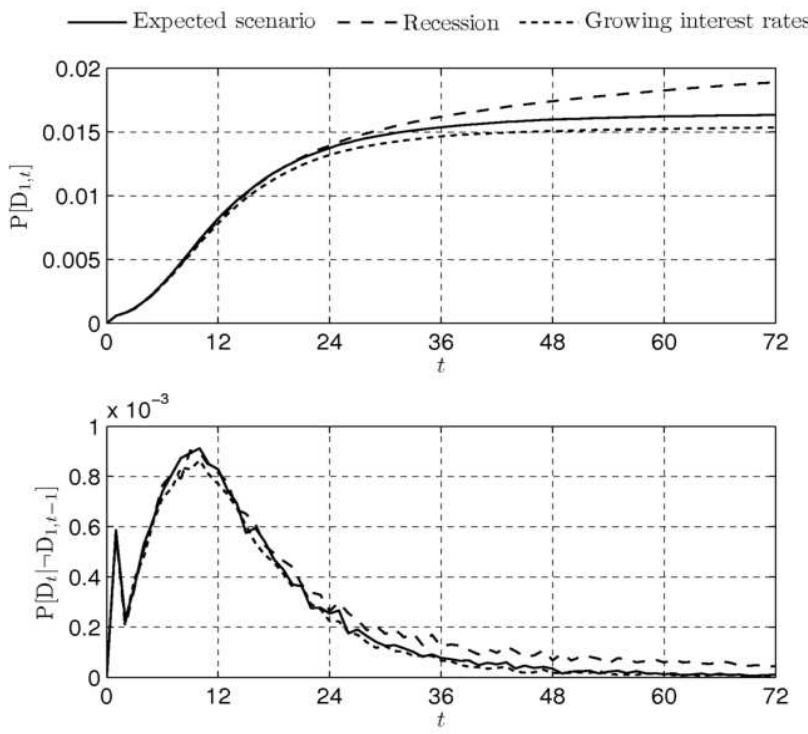